\title{
Signal properties of reinforcement and reinforcement omission on a multiple fixed-ratio schedule
}

\author{
LOUIS D. MATZEL \\ George Mason University, Fairfax, Virginia
}

\begin{abstract}
A series of experiments used food-deprived pigeons to examine several parameters of reinforcement omission in an attempt to control changes of keypeck response measures on a subsequent schedule. In Experiments 1 and 2, the pigeons were tested with a multiple fixed-ratio schedule on which reinforcement was occasionally omitted at the completion of the first component. The duration of the delay occurring in lieu of reinforcement was systematically varied. In Experiment 3 , the stimulus that signaled the second component of the schedule was altered to appear either more or less similar to the stimulus that signaled the first component. Two principal results are reported: (1) Response latency decreased and, to a much lesser extent, terminal response rate increased as the delay occurring in lieu of reinforcement decreased; and (2) both latency decrease and response-rate increase were enhanced by a second component stimulus which was similar to the first. The results are evaluated in terms of Amsel's frustration theory and an analysis by Staddon which suggests that reinforcement inhibits responding. The data appear to support Staddon's argument that rate increases and latency decreases following reinforcement omission are largely a function of an attenuation of the inhibitory influence of reinforcement, an effect that is enhanced by stimulus generalization. Accordingly, it is proposed that an animal's response to reinforcement omission is determined by a stimulus complex that minimally includes the omission event and component cues.
\end{abstract}

A number of studies have demonstrated an increase in response rate on the second "half" of a trial following the omission of an appetitive reinforcer on the first half. This effect has been reported for rats in a double alley (Amsel, 1958; Matzel, 1984), pigeons on a multiple fixedinterval (FI) schedule (Staddon \& Innis, 1966, 1969), and monkeys on a multiple fixed-ratio (FR) schedule (Davenport \& Thompson, 1965). Amsel (1962) has attributed this pattern of results to an active, motivational response evoked by the omission of an expected reinforcer. Staddon (1974), however, has argued that this effect is largely due to the attenuation of the inhibitory influence of reinforcement that occurs on an omission trial.

At least in those operant procedures that utilize FI schedules, available evidence suggests that the apparent increase in response rate following occasional reinforcement omission is the result of the removal of the inhibitory properties of reinforcement rather than enhanced motivation. Fixed-interval schedules typically produce a pause followed by gradually increased responding as the interval progresses, a pattern commonly referred to as a "scallop" (Ferster \& Skinner, 1957). Given such a pat-

This research was supported in part by George Mason University. Thanks are extended to Robert Pasnak, C. Allen Boneau, and Robert Smith for their helpful comments regarding this research, and to Ralph $\mathbf{R}$. Miller for commenting on an earlier version of the manuscript.

The author's present address is: Department of Psychology, State University of New York, Binghamton, NY 13901 tern, response latency and the ensuing response gradient are greatly diminished following instances of reinforcement omission relative to instances of reinforcement (Staddon \& Innis, 1969). The net result is an apparently higher response rate than is seen following reinforcement, an increase which Staddon and Innis have argued is due to the attenuation of the pause and the initial slow responding that is inherent in the scallop. However, given a spaced responding (DRL) schedule, characterized by a decrease in response rate as the interval progresses, responding after reinforcement omission is depressed relative to responding after reinforcement (Staddon, 1970). Staddon (1974) has argued that the motivational account of reinforcement omission, which posits that an omission of reinforcement will "energize" responding, cannot account for these results. Alternatively, if reinforcement inhibits responding, then, in the absence of reinforcement, responding should continue at the prevailing rate. The result in the FI procedure is a maintenance of the high rate typical of the later portions of this schedule. Omission of reinforcement in the DRL preparation, however, results in a maintenance of the slow response rate that prevails just prior to the time at which reinforcement is usually primed.

Additional support for this position was presented by Kello (1972), who demonstrated an omission-elicited differential response-rate increase on an FI schedule that was dependent on the manner in which the reinforcer was omitted. Response-rate increases were minimal follow- 
ing omission events most similar to reinforcement (such as a momentary hopper "flash"), and were most pronounced when the omission event was dissimilar to reinforcement. This result is contrary to the motivational account of reinforcement omission, which assumes that nonreinforcement events more similar to reinforcement should be more frustrating and should therefore evoke a greater increase in response rate. These results are predicted, however, by an analysis that assumes that reinforcement has an inhibitory influence on responding.

Staddon (1974) has suggested that these effects are attributable to a breakdown of temporal control. He posits that reinforcement is an inherently more salient stimulus than is a presumably neutral stimulus, such as a time-out. Reinforcement would therefore serve as a better temporal cue, signaling the animal that a new schedule has begun. As such, reinforcement is a time marker which controls responding; in the absence of such a marker, the prevailing response is partially maintained rather than reset. This argument implies a degree of "confusion," contributing to the rate increase that occurs in the absence of reinforcement.

The present experiments examined several parameters of reinforcement omission on a multiple FR schedule in an attempt to maximize response rate and minimize response latency on the schedule following the omission. The length of the interval that occurred in lieu of reinforcement was manipulated on the assumption, based on Staddon's analysis, that a shorter interval would act as a less salient cue marking the completion of a schedule component. The shorter intervals should therefore better facilitate the maintenance of the high response rate from the first component into the second component. Similar results were reported by Staddon and Innis (1966), who found that the maximum rate increase in response to reinforcement "omission" occurred when no delay was imposed in lieu of reinforcement. Additionally, the stimulusspecific role of the second component was examined to determine whether the similarity of the discriminative stimulus on the second component relative to the first would influence the degree to which responding was maintained following reinforcement omission on the first component. Again, if the absence of the inhibitory influence of reinforcement is the principle determinant of performance changes in these procedures, similar cues should enhance the effect by decreasing the discriminability of the two components, hence making the omission event more ambiguous. An FR, rather than an FI, schedule was examined because of the distinctly different response patterns evoked by these two schedules. Because a scallop is not typical of the FR schedule, terminal rate increases comparable to those reported in FI reinforcement omission studies might indicate an underlying process other than the mechanism described by Staddon.

\section{EXPERIMENT 1}

The effect on subsequent performance of the event occurring in lieu of reinforcement was examined. After
multiple-FR-schedule training, reinforcement was occasionally omitted upon completion of the first component. The nonreinforcement event was a 6-sec blackout, a timeout of the same duration, a $2-\mathrm{sec}$ time-out, or a $.4-\mathrm{sec}$ time-out.

\section{Method}

Subjects. The subjects were six experimentally naive, adult male White Carneaux pigeons, individually housed. Prior to the onset of the experiment, they were gradually reduced to $80 \%$ of their free-feeding weights. Supplemental feedings after each experimental session were used to maintain this level.

Apparatus. A standard Gerbrands Model G5610 operant pigeon chamber equipped with a single response key was used. Illumination was provided by a $7-W$ houselight. Key color was controlled by either a red or a green $7-\mathrm{W}$ bulb mounted directly behind the key. Reinforcement (access to mixed grain) was provided by a food magazine located below the key. The chamber was enclosed in a larger, sound-attenuating box, with continuous auditory masking provided by a ventilating fan.

Procedure. After magazine training, all birds were shaped to peck the key both when green and when red, by first reinforcing all pecks (CRF) and then gradually increasing the ratio until an FR 25 was attained. Upon completion of this training, 10 sessions of acquisition trials were begun. In the presence of the green stimulus, 25 responses extinguished the keylight and houselight while simultaneously illuminating the hopper and providing a 6-sec reinforcement. At the end of the reinforcement, the hopper light was extinguished and the houselight came on simultaneously. One second following the onset of the houselight, the red key stimulus was presented and 25 responses were reinforced as described above. After reinforcement on the second component, a 30 -sec intertrial interval (ITI) began in the illuminated chamber. Sessions were conducted on consecutive days and consisted of 25 such trials per bird per session. Session duration ranged from 30 to $40 \mathrm{~min}$.

Upon completion of this phase, reinforcement omission testing was begun on the next day. Each session consisted of 24 trials per bird, the first 4 of which were all reinforced; no data were recorded on these 4 trials. Of the remaining 20 trials in each session, reinforcement was pseudorandomly omitted at the end of the first (green) component on $50 \%$ of the trials, with the restriction that no more than three reinforcement (R) or nonreinforcement (NR) trials occur consecutively. The reinforcement omission event was one of four possibilities: (1) 6-sec blackout (keylight and houselight off); (2) 6-sec time-out (keylight off and houselight on); (3) 2-sec timeout; (4) .4-sec time-out. The second (red) component remained unchanged and began upon completion of the NR event.

A single type of NR event was used per session, each bird receiving two sessions of each type of event. The order of events was counterbalanced over an 8-day period for each bird.

Both the interval between stimulus presentation and the first response (response latency) and the response rate following the initiation of responding (terminal rate) were recorded on the second component of each trial.

\section{Results}

Figure 1 depicts the mean latencies and response rates following each of the four types of NR events relative to $\mathrm{R}$ trials from the same sessions. Each point represents data pooled from all birds.

Looking first at terminal response rate, a two-way ANOVA for repeated measures revealed that the main effect of $R$ versus NR was small and not significant $[F(1,5)$ $=2.52, \mathrm{p}>.10]$, as was the main effect of the type of NR event $[F(3,15)=.62, p>.25]$. However, terminal rate change as a function of the interaction between the 


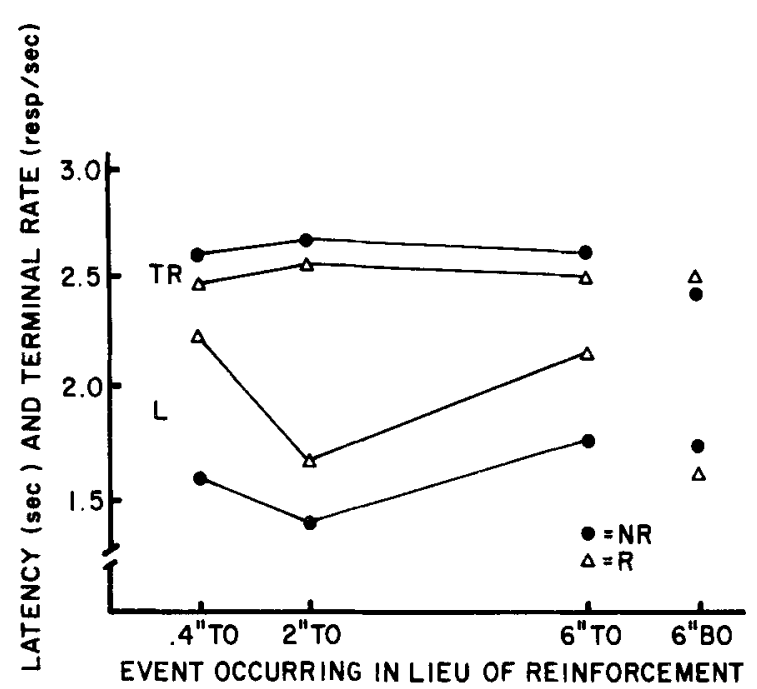

Figure 1. Second-component mean latency (L) and terminal rate (TR) following reinforcement (R) and nonreinforcement (NR) on the first component for each of four delays. The first component was signaled by a green key, and the second component was signaled by a red key.

reinforcement condition and type of NR event was significant $[F(3,15)=3.58, p<.05]$.

The effect of NR on response latency was appreciably greater. The 6-sec blackout was ineffective in reducing starting time, whereas the 6 - and 2 -sec time-outs produced comparable decreases and the .4-sec time-out yielded the greatest decrease. Both the main effect of $R$ versus NR $[\mathrm{F}(1,5)=22.97, \mathrm{p}<.005]$ and the interaction of type of NR event with reinforcement condition $[F(3,15)=$ $5.20, p<.01]$ were significant. The main effect of type of NR event was not significant $[F(3,15)=1.51, p>$ $.25]$.

The pooled data presented in Figure 1 are not entirely representative of the performance of all birds. Most of the between-subject variability occurred following the 6sec blackout. Under this condition, the direction of change in the mean terminal rate following reinforcement omission relative to reinforcement was the opposite of that suggested by Figure 1 for one of the six birds; moreover, latency changes in this condition were the opposite of those suggested by Figure 1 for two of the six birds. In the remaining three conditions, this reversal never occurred in more than one bird.

\section{Discussion}

Response latency appears to be more sensitive to the omission of reinforcement than is terminal response rate. Latency decreased an average of $30 \%$ relative to $R$ following the .4-sec NR event, whereas terminal rate increased only $4 \%$ under the same condition. It should be noted that the lack of a response-rate increase following reinforcement omission is not likely due to a ceiling effect. Across birds, average response rates varied from 1.8 to 3.5 responses/sec. Using similar subjects, Ferster and Skinner (1957) reported that pigeons were capable of responding at two to four times these rates. (This possibil- ity is further negated by the results of Experiments 2 and 3 , in which significant rate increases were observed.)

The sensitivity of response latency to reinforcement omission was demonstrated previously by Kello (1972), who concluded that such a result was inconsistent with frustration theory, since, by this account, the omission of an expected reinforcer should motivate responding per se, and hence should evoke a large terminal rate increase.

Although the main effect of reinforcement omission on terminal response rate was not reliable, the interaction between reinforcement omission and the type of NR event was significant, suggesting that terminal rate may tend to increase following NR events not involving the 6-sec blackout (the condition most similar to reinforcement). This tendency will be further examined in Experiment 2. However, if a typical FR response pattern is characterized by a pause and stable run (Ferster \& Skinner, 1957), it is difficult to interpret any rate increase solely in terms of the attenuation of the inhibitory effects of reinforcement, since, by Staddon's argument, apparent rate increases are a function of a positive goal gradient. The gradual increase typically seen early in an FI schedule is eliminated when reinforcement is omitted. Consequently, the animal continues to respond at the stable (high) rate typical of the latter portion of the schedule. Staddon would predict that, in the absence of a goal gradient, as on an FR schedule, reinforcement omission should reduce response latency, while terminal rate should remain constant. A possible explanation for the tendency toward a rate increase that was observed in the present experiment will be addressed in the Discussion of Experiment 3.

\section{EXPERIMENT 2}

The response-controlling properties of the stimulus initiating the second component of the multiple schedule as a function of reinforcement or reinforcement omission was examined in Experiment 2. The essential difference between Experiments 1 and 2 was that, in Experiment 2, both components of the multiple schedule were signaled by identical stimuli, that is, a red key. If rate changes following reinforcement omission relative to those following reinforcement were a function of a lack of cues signaling the initiation of the second component, these changes should be enhanced by a procedure using similar discriminative stimuli on each component of the multiple schedule.

\section{Method}

Subjects. The animals from Experiment 1 also served in this experiment.

Apparatus. The equipment was the same as that used in Experiment 1 , except that both the first and second components of the multiple schedule were signaled by a red key.

Procedure. After exposure and retraining on the new discriminative stimuli, consisting of four sessions of 25 reinforced trials, reinforcement omission testing was begun following the same procedure as in Experiment 1 


\section{Results}

Figure 2 illustrates the mean latencies and terminal rates for each of the four types of NR events relative to $R$ trials from the same session. Each point represents data pooled from all birds. As this figure suggests, response latency and terminal rate covaried as a function of reinforcement omission. The main effect of reinforcement omission on terminal rate across conditions $[F(1,5)=14.42, p<$ $.025]$ was significant. Neither the type of NR event $[F(3,15)=.94, p>.50]$ nor the interaction between the type of NR event and the reinforcement condition $[F(3,15)$ $=2.60, \mathrm{p}>.05]$ were significant. The main effect of the reinforcement condition on latency, $[F(1,5)=19.23$, $\mathrm{p}<.01]$ and the NR event on latency $[\mathrm{F}(1,5)=16.40$, $\mathrm{p}<.01]$ were significant, as was their interaction $[F(3,15)=23.94, p<.01]$.

The performance of all birds is well represented by the means illustrated in Figure 2 for conditions other than the 6 -sec blackout. The direction of change in the mean terminal rate following reinforcement omission relative to reinforcement in this condition was the opposite of that suggested by Figure 2 in one of the six birds; latencies in this condition were the opposite of that represented in the figure in two of the six birds. Of the remaining three conditions, all birds responded in the manner indicated by the figure.

\section{Discussion}

While both measures were in the same direction as in Experiment 1, the magnitude of the effects increased sub-

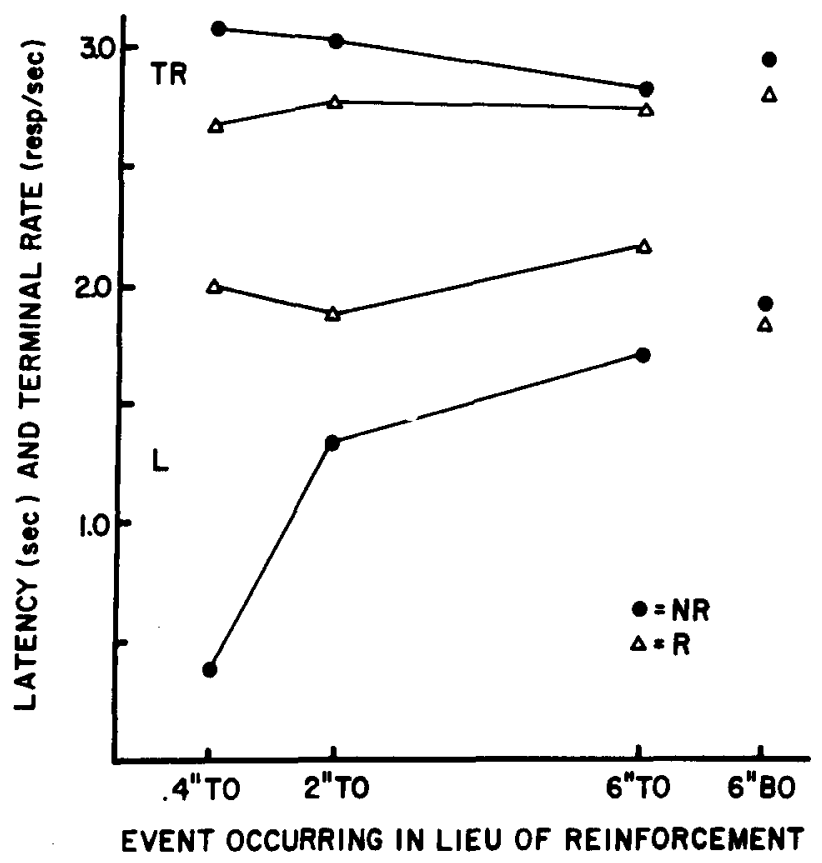

Figure 2. Second-component mean latency ( $L$ ) and terminal rate (TR) following reinforcement (R) and nonreinforcement (NR) on the first component for each of four delays. Both components were signaled by a red key. stantially. The greatest effect was again observed after the .4-sec time-out for both measures. A comparison of the two experiments shows that although the .4-sec timeout resulted in a mean rate increase of $4 \%$ in Experiment 1 , the same condition produced an increase of $14 \%$ in Experiment 2. The .4-sec time-out resulted in a mean latency decrease of $30 \%$ in Experiment 1 and one of $80 \%$ in Experiment 2.

These two experiments suggest that omission-elicited latency decreases on a multiple FR schedule are enhanced by a decreasing NR interval. Under similar circumstances, response-rate increases occur less reliably. For both measures, the main effect of reinforcement omission appears to be enhanced if the stimuli signaling both components are similar.

\section{EXPERIMENT 3}

Experiment 3 was intended to provide a direct measure of similarity between the first and second component stimuli as a determinant of response changes after reinforcement omission.

\section{Method}

Subjects. The animals from Experiments 1 and 2 also served in this experiment.

Apparatus. The apparatus was identical to that of the previous two experiments except that the second component was signaled by either a red or a green key. The first component remained red.

Procedure. The pigeons were exposed to a multiple FR schedule similar to that used in the previous two experiments. The first component signal was always red, and the second component signal was either red or green. The color was pseudorandomly determined, with the restriction that $50 \%$ of the trials be signaled by each stimulus and that neither color occur on more than three consecutive trials. Four sessions of 40 trials each were employed to adapt the birds to this procedure. During this retraining, one bird was injured in the home cage and was dropped from the study.

Test sessions consisted of pseudorandom reinforcement omission on the first component of $50 \%$ of the trials. Reinforcement omission took the form of a .7-sec time-out. On both R and NR trials, the second component signal was either red or green on $50 \%$ of the trials. No reinforcement condition occurred more than three times consecutively, and no reinforcement condition $\times$ color combination occurred more than twice consecutively. Each bird received 40 trials per session, one session on each of 2 consecutive days. The first four trials of both test sessions were reinforced and were excluded from the data pool.

\section{Results}

The stimulus-specific role of the second component on performance evoked by reinforcement omission is summarized in Table 1. As in Experiment 2, terminal response-rate increases as a function of reinforcement omission were small but significant $[F(1,4)=19.74, p<$ $.025]$. Latency decreases were substantially larger $[F(1,4)$ $=10.75, \mathrm{p}<.05]$. As suggested in Experiment 2, both effects were enhanced by a second component color similar to that of the first component. The reinforcement condition $\times$ component color interaction was significant for terminal rate $[F(1,4)=7.88, p<.05]$ and for response latency $[F(1,4)=9.37, p<.05]$. 
Table 1

Terminal Rate and Latency Means on Red and Green Components After Reinforcement (R) and Reinforcement Omission (NR) on a Red Component

\begin{tabular}{|c|c|c|c|c|c|c|}
\hline \multirow[b]{2}{*}{ Condition } & \multicolumn{3}{|c|}{$\begin{array}{c}\text { Terminal Rate } \\
\text { (Responses/Second) }\end{array}$} & \multicolumn{3}{|c|}{$\begin{array}{c}\text { Latency } \\
\text { (Seconds) }\end{array}$} \\
\hline & Mean & $\mathrm{D}$ & Increase & Mean & D & Decrease \\
\hline NR/Red & 3.30 & & & .86 & & \\
\hline R/Red & 2.96 & .34 & $11 \%$ & 1.82 & .96 & $53 \%$ \\
\hline NR/Green & 2.87 & & & 1.03 & & \\
\hline R/Green & 2.81 & .06 & $2 \%$ & 1.50 & .47 & $31 \%$ \\
\hline
\end{tabular}

\section{Discussion}

The principal effect found in Experiment 3 was that terminal rate increases and latency decreases were greater if the component cue following reinforcement omission was similar to the component cue prior to the omission. This provides direct support for the hypothesis that an animal's response to reinforcement omission is determined by a stimulus complex that minimally includes the omission event and component cues. As Staddon (1974) posits, a presumably neutral stimulus (in this case a time-out) is inherently less salient to a hungry animal than is a food reinforcement, an assumption that has since found empirical support (Spetch \& Wilkie, 1981). However, the neutral stimulus can interact with other stimuli, in this case a change of key color, to signal the initiation of a new schedule component. In the absence of any cue, that is, reinforcement or key-color change, responding is maintained at a high rate.

In order for an animal to actively respond to an instance of reinforcement omission, that omission must be discriminable. That the rate increases and latency decreases reported here were greatest when conditions were such that the omission of reinforcement was least discriminable stands in contradiction to a motivational account of this effect. Nevertheless, although terminal rate changes were small relative to latency changes following reinforcement omission, terminal rate increases have been demonstrated both here and elsewhere (Davenport \& Thompson, 1965) on FR schedules. Based on the data reported here, which support the theory that reinforcement inhibits responding, an account of this small rate increase which does not depend on enhanced motivation seems appropriate.

One possibility is that rate increases following reinforcement omission on an FR schedule may be the result of the attenuation of the erratic performance typical of responding in the early portions of the schedule. Although stable responding may be the ideal conceptualization of the FR response pattern, terminal rate is often not achieved at the onset of responding (Ferster \& Skinner, 1957). In an analysis comparable to that applied by Staddon to the FI schedule, responding on the second component following reinforcement omission on the FR schedule should continue at the rate that immediately preceded the omission. As reinforcement omission eliminates the scallop on the FI schedule, it should similarly eliminate (or reduce) the variable responding typically observed early in an FR schedule, effectively increasing response rate. (Such an argument assumes that since the bird is responding at a stable rate following reinforcement omission, the more variable responding following reinforcement would translate into slower response rates, i.e., erratic responding should not result in a rate increase.) An examination of standard deviations reveals more variance on $R$ trials $(s=1.89)$ than on NR trials $(s=1.42)$ employing similar component colors. Although this difference is small, it is likely to have been diminished by the stable (less variable) responding typical of the later portions of the schedule. This analysis predicts a small rate increase relative to that observed following reinforcement omission on FI schedules, on which rate increases of $100 \%$ are common, since the initial portions of the pronounced goal gradient can be attenuated on the interval schedule.

A second alternative explanation of this small rate increase (which is not incompatible with the notion of decreased response variability) relies on a peak shift (e.g., Hanson, 1959; Terrace, 1964) analysis of the multiple ratio schedule. The FR schedule employed in this study represents an asymmetrical discrimination in which the animal is never reinforced for a given response that falls below the ratio requirement ( $\mathrm{S}-$ ), but is always reinforced (at least during training) for the 25th response. However, the animal never experiences reinforcement, and so is never not reinforced for responses beyond this requirement. On subsequent test trials, reinforcement is occasionally omitted and the animal is exposed to what is essentially an extended ratio, in which response 50 is reinforced. Such a sequence may produce a peak shift, resulting in a maximum response rate at a point shifted from $\mathrm{S}+$ in a direction away from $\mathrm{S}-$, effectively resulting in a rate increase during that portion of the schedule defined as the second component. However, this explanation may be more applicable to experiments employing FI schedules than to those employing FR schedules, since responding in FI schedules typically increases throughout the interval. Maximum rate is therefore more likely to shift beyond the time at which food is usually primed. Such a response gradient is not inherent to FR schedules, thereby limiting the viability of this analysis in the present case. However, on the basis of the argument that response rates are not entirely stable throughout the ratio, the peak shift may contribute to this effect.

Pertinent to this issue is a report by Roberts (1981, Experiment 4), who has used a "peak procedure" that results in a symmetrical response distribution around the time at which reinforcement is primed on a modified interval schedule (for an additional description of this procedure and its rationale, see also Roberts \& Church, 1978). Peak time, or the time in the interval at which the highest response rate (peak rate) was reached, occurred earlier in a trial following an instance of reinforcement omission than in one following reinforcement. However, peak response rate did not increase. Both of these results are predicted by Staddon's analysis. Since this procedure al- 
lows the animal to respond (without reinforcement) beyond the time at which reinforcement is primed, pre- and postreinforcement times each serve as an instance of $\mathrm{S}$ - , thereby eliminating the possibility of a rate increase as the result of a peak shift, which, in fact, did not occur. Roberts concludes that food acts to reset the animal's internal clock which times the interval duration. When food is occasionally omitted, the clock is not reset, and responding is maintained as though food were still forthcoming. This interpretation is consistent with the data reported here and with Staddon's analysis of the omission effect.

\section{GENERAL DISCUSSION}

It seems reasonable to conclude that the ongoing response pattern on an FR schedule is controlled, to a large degree, by reinforcement. When reinforcement is omitted, the animal will continue to respond beyond the point at which reinforcement was scheduled. Analogously, the presentation of an unscheduled reinforcer results in a subsequent decrease in response rate (Zimmerman, 1971). The alternative to the conclusion that responding is controlled by reinforcement per se is the possibility that the animal "expects" a particular response to produce the reinforcer and responds according to this expectation. In accord with the data reported here, which render this possibility unlikely, Davis and Memmott (1983) provide evidence that infrahuman animals are contraprepared (Seligman, 1970) to count, will do so only when a more salient source of information is not available, and are able to do so only over short spans. Specifically, they find that rats will count as high as "three" to predict safety from shock only when temporal cues or discrete stimuli are not equally predictive. Prior to omission testing, reinforcement fully predicts the termination of the schedule component in the current studies.

It appears, then, that the animals come to associate reinforcement with the termination of a schedule, the response to which is a pause prior to the reinitiation of responding. In the absence of this cue, responding is not inhibited and the pause (latency) is substantially reduced. Two factors were shown to influence this effect: (1) the length of the delay occurring in lieu of reinforcement, and (2) those stimulus-specific features of the schedule following an omission which distinguish it from the preceding schedule. The conclusion to be drawn from these results is that reinforcement differentiates between the components of a schedule. In the absence of reinforcement, the subject may fail to discriminate this transition; short delays and second-component stimuli similar to the first component facilitate this lack of discrimination, that is, they make the transition more difficult to perceive.

Staddon (1974) has used similar logic to argue against the "Wagner control" (Wagner, 1959) procedure which provided results commonly cited as evidence against the possibility that reinforcement inhibits responding. Wagner found that rats that were never reinforced in the first goal- box of a double runway ran more slowly to the second goalbox than did experimental rats that had experienced reinforcement omission in the first goalbox following a history of continuous reinforcement. During training, all rats in Wagner's study were detained in the first goalbox after traversing Runway A (the first component). While the experimental animals received a food reinforcement in this goalbox, the control animals spent a comparable length of time in the empty goalbox prior to being allowed access to Runway $B$ (the second component). In the absence of a more salient cue, the control animals may have come to differentiate between the two components, using goalbox cues other than food. But, as Mackintosh (1975) suggests, a more salient cue, such as food for the hungry animal in the experimental group, may come to control responding at the expense of less valued (or salient) stimuli. In this manner, the experimental animals may have come to associate food with the termination of the first component at the expense of learning about other cues present in the goalbox, an effect analogous to overshadowing (Kamin, 1969). The result would be that the two groups would come to rely on different cues to distinguish between components. On subsequent reinforcement-omission trials, however, the experimental animals would lack their primary discriminative cue. On this occasion, the overshadowed goalbox cues would not provide a sufficiently salient cue to terminate responding, resulting in a diminution of the positive goal gradient in the second component and an apparent rate increase relative to the control animals.

In summary, Experiments 1, 2, and 3 all report results that are incompatible with frustration theory. For an animal to be frustrated by an instance of reinforcement omission, the animal must be sensitive to that omission. By Amsel's (1962) definition, the omission of an expected reinforcer is a discriminable event which the frustrated animal actively responds to. Furthermore, this argument implies that instances of reinforcement omission that are most similar to instances of reinforcement should be most frustrating and, hence, should evoke the greatest rate increase. All of the experiments presented here demonstrated that the greatest performance changes in response to reinforcement omission occurred when the parameters were such that the animal was least likely to perceive the omission, that is, when the omission event and the surrounding stimulus complex were least distinct. Rate increases and latency decreases under these circumstances (and in these operant procedures) appear to be solely a function of disinhibition and stimulus generalization.

\section{REFERENCES}

AMSE L, A. (1958). The role of frustrative nonreward in noncontinuous reward situations. Psychological Bulletin, 55, 102-119.

AMSEL, A. (1962). Frustrative nonreward in partial reinforcement and discrimination learning: Some recent history and a theoretical extension. Psychological Review, 69, 306-328.

Davenport, J. W., \& Thompson, C. I. (1965). The Amsel frustration effect in monkeys. Psychonomic Science, 3, 481-482. 
Davis, H. \& Memmott, J. (1983). Autocontingencies: Rats count to three to predict safety from shock. Animal Learning \& Behavior, 11, 95-100.

FERSter, C. B., \& SKINNER, B. F. (1957). Schedules of reinforcement. New York: Appleton-Century-Crofts.

Hanson, H. M. (1959). Effects of discrimination training on stimulus generalization. Journal of Experimental Psychology, 58, 321-334.

Kamin, L. J. (1969). Predictability, surprise, attention, and conditioning. In B. A. Campbeil \& R. A. Church (Eds.), Punishment and aversive behavior. New York: Appleton-Century-Crofts.

KELLO, J. E. (1972). The reinforcement omission effect on fixed interval schedules: Frustration or inhibition? Learning and Motivation, 3, 138-147.

Mackintosh, N. J. (1975). A theory of attention: Variations in the associability of stimuli with reinforcement. Psychological Review, 82 . 276-298.

MATZEL, L. D. (1984). Aggression in rats as a function of target location in a double alley. American Journal of Psychology, 97, 519-526.

ROBERTS, S. (1981). Isolation of an internal clock. Journal of Experimental Psychology: Animal Behavior Processes, 7, 242-268.

Roberts, S., \& Church, R. M. (1978). Control of an internal clock. Journal of Experimental Psychology: Animal Behavior Processes, 4 , 318-337.

Seligman, M. E. P. (1970). On the generality of laws of learning. Psychological Review, 77, 406-418.
Spetch, M. L., \& Wilkie, D. M. (1981). Duration discrimination is better with food access as the signal than with light as the signal. Learing and Motivation, 12, 40-64.

STADDON, J. E. R. (1970). Temporal effects of reinforcement: A negative "frustration" effect. Learning and Motivation, 1, 227-247.

Staddon, J. E. R. (1974). Temporal control, attention, and memory. Psychological Review, 81, 375-391.

StadDON, J. E. R., \& INNIS, N. K. (1966). An effect analogous to "frustration" on interval reinforcement schedules. Psychonomic Science, 4, 287-288.

Staddon, J. E. R., \& INNIS, N. K. (1969). Reinforcement omission on fixed-interval schedules. Journal of the Experimental Analysis of Behavior, 12, 689-700.

TERRACE, H. S. (1964). Wavelength generalization after discrimination learning with and without errors. Science, 144, 78-80.

WAGNER, A. R. (1959). The role of reinforcement and nonreinforcement in an "apparent frustration effect." Joumal of Experimental Psychology, 57, 130-136.

Zimmerman, D. W. (1971). Rate changes after unscheduled omission and presentation of reinforcement. Journal of the Experimental Analysis of Behavior, 15, 261-270.

(Manuscript received November 28, 1984; revision accepted for publication May 6, 1985.) 